\title{
Dietary soy protein induces hepatic lipogenic enzyme gene expression while suppressing hepatosteatosis in obese female Zucker rats bearing DMBA-initiated mammary tumors
}

\author{
Reza Hakkak • Ahmed Al-Dwairi • George J. Fuchs • \\ Soheila Korourian • Frank A. Simmen
}

Received: 16 January 2012/ Accepted: 31 March 2012/Published online: 24 April 2012

(C) Springer-Verlag 2012

\begin{abstract}
Fatty liver is associated with obesity and breast cancer. We used an obese rat model of mammary cancer to examine whether hepatosteatosis is modifiable by diet and associated with altered expression of hepatic lipogenic enzyme genes, thyroid hormone system genes and cholesterol metabolism-related genes. Beginning at the age of 5 weeks, lean and obese female Zucker rats were fed high-isoflavone soy protein- or casein (control protein)containing diets. Rats were euthanized at 200 days of age [corresponding to 147 days after administration of
\end{abstract}

Reza Hakkak and Ahmed Al-Dwairi: Co-first authors.

R. Hakkak ( $\bowtie)$

Department of Dietetics and Nutrition, University of Arkansas for Medical Sciences, 4301 W. Markham St., Mail Slot 627, Little Rock, AR 72205, USA

e-mail: HakkakReza@uams.edu

R. Hakkak · G. J. Fuchs

Department of Pediatrics, University of Arkansas for Medical

Sciences, Little Rock, AR 72205, USA

e-mail: Fuchsgeorge@uams.edu

R. Hakkak

The Arkansas Children's Hospital Research Institute, University of Arkansas for Medical Sciences, Little Rock, AR 72205, USA

\section{A. Al-Dwairi · F. A. Simmen $(\bowtie)$}

Department of Physiology and Biophysics,

University of Arkansas for Medical Sciences,

4301 W. Markham St., \#505, Little Rock, AR 72205, USA

e-mail: simmenfranka@uams.edu

A. Al-Dwairi

e-mail: aaldwairi@uams.edu

\section{S. Korourian}

Department of Pathology, University of Arkansas for Medical

Sciences, Little Rock, AR 72205, USA

e-mail: KorourianSohelia@uams.edu carcinogen to induce mammary tumors; (Hakkak et al. in, Oncol Lett 2:29-36, 2011)]. Obese rats had a greater degree of liver steatosis than lean rats. Obese casein-fed rats had marked steatosis with small foci of mononuclear infiltration, whereas obese soy protein-fed rats had a significantly lower steatosis index. Comparisons between lean and obese casein-fed rats showed that obesity was associated with significant reductions in hepatic mRNA abundance for Glucose 6-Phosphate Dehydrogenase (G6PD), 6-Phosphogluconate Dehydrogenase (6PGD), Thyroid Receptor Alpha 1 (TR $\alpha 1)$, Thyroid Receptor Beta 1 (TR $\beta 1)$ and Iodothyronine Deiodinase 1 (DIO1). The soy protein diet was associated with increased expression of Fatty Acid Synthase (FASN), Malic Enzyme 1 (ME1), 6PGD, Sterol Regulatory Element Binding Protein-1c (SREBP-1c) and SREBP-2 genes in the livers of obese but not lean rats. Western blot analysis showed a significant induction of ME1 protein expression in the livers of obese, soy protein-fed rats, which paralleled the increased serum insulin level in this group. Long-term soy protein consumption can counter hepatic steatosis while coincidently promoting hepatic lipogenic gene expression, the latter likely a consequence of elevated serum insulin. We suggest that elevations in serum insulin, hepatic lipogenesis and cholesterol synthesis all contributed to the increased tumorigenesis previously observed for the obese, soy protein-fed rats.

Keywords Soy - Rats - Fatty acid synthase · Malic enzyme $1 \cdot$ Steatosis $\cdot$ Insulin $\cdot$ NAFLD

\section{Introduction}

Obesity has been epidemic in the United States for more than two decades with the proportion of overweight and 
obese adults in the population continuing to increase. Data from the 1999-2000 National Health and Nutrition Examination Survey (NHANES) showed that nearly $65 \%$ of adults in the United States were overweight, as defined by a body mass index (BMI) greater than $25 \mathrm{~kg} / \mathrm{m}^{2}$ (Mokdad et al. 2003). This was a significant increase from $56 \%$ as reported in NHANES III (1988-1994) (Sinha et al. 1996). Results from the 2005-2006 NHANES, using measured heights and weights, indicated that an estimated $32.7 \%$ of US adults 20 years and older were overweight (BMI 25.0-29.9 kg/m²), 34.3\% were obese (BMI 30.0$39.9 \mathrm{~kg} / \mathrm{m}^{2}$ ) and $5.9 \%$ were extremely obese (BMI $\geq$ $40 \mathrm{~kg} / \mathrm{m}^{2}$ ) (National Center for Health Statistics. [http:// www.cdc.gov/nchs/nhanes.htm]). Many countries have experienced similar dramatic increases in obesity (WHO [http://www.who.int/nut/obs.htm]). Worldwide, more than one billion adults are estimated to be overweight, and over 300 million to be obese. This trend has alarming health implications, as obesity is associated with serious health conditions, including type 2 diabetes, cardiovascular disease, some cancers including those of the breast, uterus and colon, hyperlipidemia and nonalcoholic fatty liver disease (Mokdad et al. 2003).

Fatty liver disease shows a range of morphological features including fatty liver (liver steatosis) to fatty liver associated with inflammation. These conditions can occur with the use of alcohol (alcohol-related fatty liver) or in the absence of alcohol (nonalcoholic fatty liver disease, NAFLD). NAFLD consists of various histological changes from simple steatosis to steatosis with inflammation and cellular injury (steatohepatitis), fibrosis and cirrhosis. NAFLD is now the most common cause of liver pathology with a prevalence of up to $34 \%$ in the United States; however, this increases to greater than $50 \%$ in the obese population (Browning et al. 2004; Ong and Younossi 2007). NAFLD is associated with insulin resistance, which, in turn, is associated with metabolic syndrome and Type 2 diabetes (Browning et al. 2004). NAFLD can be asymptomatic or can progress to steatohepatitis followed by fibrosis and can eventually cause cryptogenic cirrhosis. The prevalence of fatty liver disease is estimated at 10-20\% of the population, and this condition affects both women and men (Angulo 2002) and children (Roberts 2007). Population-based studies have shown that approximately $5 \%$ of patients who initially present with fatty liver, eventually develop steatohepatitis (Day 2005). Liver steatosis is found at increased prevalence in women with breast cancer, although the nature of this association and any cause and consequence relationship(s) remain obscure (Bilici et al. 2007; Chu et al. 2003; Nguyen et al. 2001).

The Zucker rat $(f a / f a)$ is perhaps the most widely used rat model for obesity and diabetes research (Zucker and Zucker 1961, 1963). Obesity in the Zucker rat is inherited as an autosomal recessive trait and is caused by a mutation in the leptin receptor gene (Chua et al. 1996; Tartaglia et al. 1995). Animals homozygous for the $f a$ allele become noticeably obese by age 3-5 weeks, and by age 14 weeks their body composition is more than $40 \%$ lipid (Zucker 1972). The Zucker rat has been used as a model of human early-onset, hyperplastic-hypertrophic obesity. Many investigators have used this animal model to study the development, etiology, associated pathologies, possible treatments and contributing mechanisms of severe obesity (Bray et al. 1989). In addition, this animal model develops hepatic steatosis (Tovar et al. 2005) due to dysregulated metabolic gene expression in the liver (Buque et al. 2010); to the best of our knowledge, this has not been previously studied within the context of an imposed carcinogenic/cancer state.

Many studies have suggested health benefits from soy consumption, including its roles in reducing risk of cardiovascular disease and certain types of cancers (Hakkak et al. 2000; Kris-Etherton et al. 2002; Simmen et al. 2005) and its hypo-cholesterolemic and anti-inflammatory effects (Anderson et al. 1995; Ascencio et al. 2004; Gudbrandsen et al. 2005, 2006, 2009; Simmen et al. 2010; Tovar et al. 2002; Zhan and Ho 2005). Soybeans and soy protein products are a major source of a class of phytoestrogens, namely the isoflavones. Isoflavones are structurally similar to estrogens, exhibit estrogenic and anti-estrogenic properties, and are potential anti-cancer molecules (Peeters et al. 2003). We and others have reported effects of highisoflavone soy protein-containing diets on hepatic gene expression and hepatic lipid contents in rat and mouse models (Simmen et al. 2010). Here, we evaluated in female Zucker rats bearing mammary tumors, the effects of obesity status and soy protein-based diet on (a) the development of liver steatosis, (b) liver expression of lipogenic enzyme, thyroid hormone system and selected cholesterol metabolism-related genes and (c) serum insulin levels, in order to model potential dietary attenuation of hepatosteatosis in women with breast cancer. We hypothesized that obesity would lead to elevations in hepatic lipogenic enzyme gene expression, suppressions in hepatic thyroid hormone system gene expression and increased circulating insulin levels in this model of breast cancer. Further, we hypothesized that long-term soy consumption (a highisoflavone scenario) would provide protection against liver steatosis in obese tumor-bearing rats.

\section{Materials and methods}

Experimental design

Animal protocols were approved by the Institutional Animal Care and Use Committee of the University of Arkansas 
for Medical Sciences. A total of 99 five-week-old female Zucker rats (45 obese $f a / f a$ and 54 lean) were obtained from Harlan Industries (Indianapolis, IN). Harlan Industries performed genotyping to identify $\mathrm{fa} / \mathrm{fa}$ and lean/lean rats at the age of 24 days. After 1 week of acclimation (age 42 days), rats were randomly assigned to the following groups: (1) lean, casein diet; (2) obese, casein diet; (3) lean, soy protein diet; and (4) obese, soy protein diet. Rats were housed 2 per cage with ad libitum access to water and semi-purified diet. The semi-purified diet was similar to the AIN-93G diet formulation (Harlan Teklad, Madison, WI) and was prepared with equivalent amounts of dietary protein, either casein (control) or a partially hydrolyzed soy protein isolate with high-isoflavone content [3.24 mg total isoflavones/g protein (1.88 aglycone equivalents/g protein), Lot\#M330024462; Solae LLC, St. Louis, MO]. The compositions of both diets are described in Table 1 [and in (Hakkak et al. 2011)]. At 50 days of age, all rats, as part of an experiment examining the effects of high-isoflavone soy protein diet and obesity on mammary tumor development (Hakkak et al. 2011), received the carcinogen 7,12-dimethylbenz $(a)$ anthracene (DMBA, Sigma Chemical Co., St. Louis, MO), via gavage (65 mg DMBA/kg body weight in sesame oil). Rats were euthanized at approximately 200 days of age. Livers were removed and weighed. Two 3-mm sections of each lobe of each liver were fixed in $10 \%$ buffered formalin and processed for light microscopic evaluation. From these, 5- $\mu$ m liver sections were cut and stained with hematoxylin and eosin. Tumor parameters

Table 1 Composition of study diets (Hakkak et al. 2011)

\begin{tabular}{lll}
\hline Ingredients & Casein $(\mathrm{g} / \mathrm{kg})^{\mathrm{a}}$ & Soy protein $(\mathrm{g} / \mathrm{kg})$ \\
\hline Casein & 200 & - \\
Isolated soy protein & - & 202 \\
L-Cystine & 3.0 & 1.3 \\
L-Methionine & - & 2.5 \\
L-Tryptophan & - & 0.4 \\
L-Threonine & - & 0.3 \\
Corn starch & 397.50 & 409.00 \\
Maltodextrin & 132.0 & 132.0 \\
Sucrose & 100.0 & 108.0 \\
Corn oil & 70.0 & 63.0 \\
Cellulose & 50.0 & 50.0 \\
AIN-93 G Mineral mix & 35.0 & 35.0 \\
AIN-93 G Vitamin mix & 10.0 & 10.0 \\
Choline bitartrate & 2.5 & 2.5 \\
TBHQ, antioxidant & 0.014 & 0.014 \\
\hline
\end{tabular}

a Gram of ingredient $/ \mathrm{kg}$ of diet

b The amount of corn oil was adjusted in the soy protein diet to account for the fat contribution from soy protein noted for this study have been recently described (Hakkak et al. 2011).

Pathology

A board-certified anatomic pathologist (S.K.) evaluated each liver section in blinded fashion. Livers were evaluated for presence of micro- and macrosteatosis, inflammatory infiltrates and fibrosis. The percentage of liver cells showing fat accumulation was estimated. A score of 1-4 was given to each section, based on the relative degree of steatosis in hepatocytes: $1(<25 \%), 2(25-50 \%), 3$ $(51-75 \%)$ and $4(>75 \%)$.

RNA isolation and quantitative real-time polymerase chain reaction (qRT-PCR)

RNA ( $n=9$ animals per group) was extracted using TRIZol reagent (Invitrogen) and $1 \mathrm{ug}$ of total RNA from each animal was reverse transcribed to cDNA using iScript cDNA synthesis reagents (Bio-Rad). Two independent sets of cDNAs [ $n=9$ per group (Fig. 2) and a subset of $n=7$ per group (Fig. 4)] were synthesized. Expression of target genes was assayed by qRT-PCR, using Bio-Rad iTaq SYBR Green Supermix. Two independent runs were performed for each gene. PCR primers (Table 2) were obtained from Integrated DNA Technologies. mRNA abundance was normalized to the geometric means of $18 \mathrm{~S}$ rRNA or $\beta$-actin and Cyclophilin A and TATA box binding protein (TBP) gene expression values and was calculated using GeNorm software (Vandesompele et al. 2002).

Protein isolation and Western blot analysis

Liver tissue was homogenized in Radio-Immunoprecipitation Assay (RIPA) buffer containing protease inhibitor cocktail (Santa Cruz Biotechnology), and protein concentration was determined using the BCA protein assay (Pierce). Fifty $\mu \mathrm{g}$ of protein was separated by $8 \%$ SDSPAGE gel electrophoresis and transferred to a nitrocellulose membrane. An anti-human ME1 antibody (Abcam) was diluted in $5 \%$ nonfat dry milk in Tris-buffered saline with Tween (TBST). Membranes were incubated with the diluted antibody overnight at $4{ }^{\circ} \mathrm{C}$, after blocking in $5 \%$ nonfat dry milk for $1 \mathrm{~h}$. Membranes were then washed and incubated with horseradish peroxidase-conjugated secondary antibody (Santa Cruz Biotechnology), and immunoreactive proteins were visualized by chemiluminescence (Amersham Bioscience). Membranes were stripped, blocked with $5 \%$ nonfat dry milk for $1 \mathrm{~h}$, washed and incubated with antibody to $\beta$ actin (loading control). ME1 and $\beta$ actin bands were quantified with Quantity One software (Bio-Rad). 
Table 2 Primers used in qRT-PCR

\begin{tabular}{|c|c|c|}
\hline Gene & Forward primer $\left(5^{\prime}-3^{\prime}\right)$ & Reverse primer $\left(5^{\prime}-3^{\prime}\right)$ \\
\hline$\beta$ actin; $A c t B$ & CAGCCTTCCTTCCTGGGTATG & TAGAGCCACCAATCCACACAG \\
\hline Cholesterol $7 \alpha$-hydroxylase; Cyp $7 a 1$ & ACACGCTCTCCACCTTTG & GCTTTCATTGCTTCAGGACTC \\
\hline Deiodinase, iodothyronine, type I; Diol & GTGATACAGGAAGGCAGGATC & CCTAGAACTGAGGCATGTGTC \\
\hline Deiodinase, iodothyronine, type II; Dio2 & CTCCTAGACGCCTACAAACAG & TGCTTCAGGATTGGACAC G \\
\hline Fatty acid synthase; Fasn & AATTGCCCGAGTCAGAGAAC & ACAGATCCTTCAGCTTTCCAG \\
\hline Glucose-6-phosphate dehydrogenase; G6pd & AGAGGTGGAAACTGACAACG & GCAAAGGTAGCAGTGGTAGAC \\
\hline 3-hydroxy-3-methyl-glutaryl-CoA reductase; $\mathrm{Hmgcr}$ & GCCTCGACCTAATGAAGAGTG & AGTTTGTAGGCTGGGATGTG \\
\hline Liver $\mathrm{X}$ receptor alpha; $\mathrm{Nr} 1 \mathrm{~h} 3$ & AGTGCCTGATGTTTCTCCTG & AАСССТАТССТTAAAGCACCC \\
\hline Malic enzyme 1, NADP(+)-dependent, cytosolic; Me1 & CAACTCCTATGTGTTCCCTGG & TGACACTTGCTGGGATATGAC \\
\hline Phosphogluconate dehydrogenase; $P G D$ & TTGCTCGGTGCTTGTCTTCTCTGA & TGGAAGCATAAAGGGCCTTACGGA \\
\hline Cyclophilin A; Ppia & AAGCATACAGGTCCTGGCATCT & TGCCATCCAGCCACTCAGT \\
\hline $\begin{array}{l}\text { Sterol regulatory element binding transcription factor } 1 \text {; } \\
\text { Srebf1 (Srebp-1c) }\end{array}$ & CACAGCAACCAGAAACTCAAG & AGCGTTTCTACCACTTCAGG \\
\hline $\begin{array}{l}\text { Sterol regulatory element binding protein-2; Srebf } 2 \\
\text { (Srebp2) }\end{array}$ & СТСТССТТТААССССТТGАСТТС & TCAAACCAGCCTCCAGAAC \\
\hline Thyroid hormone receptor $\alpha$; Thra & CAAGGTGGAGTGTGGGTCAGA & CCCTGACATGCTGCTTTTCAG \\
\hline Thyroid hormone receptor beta; $T h r b$ & GAGTGGTGGATTTCGCCAAA & GAGGGACATGATCTCCATGCA \\
\hline TATA box binding protein; $T b p$ & CACCAATGACTCCTATGACCC & CAAGTTTACAGCCAAGATTCACG \\
\hline 18S Ribosomal RNA & ATTCGAACGTCTGCCCTATCAA & CGGGAGTGGGTAATTTGC \\
\hline
\end{tabular}

Serum insulin measurements

Serum insulin was measured using a rat/mouse insulin ELISA (Millipore). Samples were run in duplicate (8-10 animals/group). Serum samples from the obese animal groups were diluted 1:5 with assay buffer prior to assay to ensure that the values fell within the corresponding standard curve.

\section{Statistical analysis}

A Kruskal-Wallis test was used to analyze for differences between treatment groups followed by between-group comparisons using the Mann-Whitney $\mathrm{U}$ test, due to unequal variances in the groups. Statistical significance was set at $P<0.05$, and $P$ values were not adjusted for multiple comparisons. Data analyses were performed using SPSS $($ ) version 17.0 for Windows (SPSS Inc., Chicago, IL). Two-way ANOVA was used to compare abundance of mRNAs and protein bands between groups.

\section{Results}

Liver weights

We previously reported the growth curves, body weights and mammary tumor data for the animals studied here
(Hakkak et al. 2011). Obese rats gained significantly more weight than lean rats and at termination of the study, the obese soy-fed rats were significantly heavier than the obese casein-fed rats. The lean soy-fed rats had higher body weight than lean casein-fed rats. Moreover, obese caseinfed rats had a significantly higher liver weight (when expressed as absolute weight or as percent of body weight) than the lean casein-fed rats (Table 3). Obese rats fed the soy diet had significantly lower liver weight (expressed as absolute liver weight or percent of the body weight) compared to obese casein-fed rats (Table 3). In the lean groups, soy-fed rats had significantly lower liver weight only as percent of the body weight when compared to casein-fed rats. Also, lean soy-fed rats had significantly lower liver weight both as absolute weight and as percent of the body weight compared to the obese soy-fed group. Thus, obesity caused a significant increase in liver weight and the soy diet lowered liver weights in both the lean and obese groups. However, the soy diet enhanced overall body weight for both lean and obese Zucker rats.

Liver histopathology

Figure 1 shows representative hepatic parenchyma. The obese casein-fed rats had a significantly higher steatosis score when compared to the lean casein-fed rats (Table 3). However, obese soy-fed rats had a significantly lower steatosis score than the obese casein-fed rats. Also, the lean 
Table 3 Liver weights and pathology scores (mean \pm SE)

\begin{tabular}{llrrr}
\hline & Lean casein $(n=26)^{*}$ & Lean soy $(n=28)$ & Obese casein $(n=20)$ & Obese soy $(n=25)$ \\
\hline Liver weight & & & & \\
Absolute weight $(\mathrm{g})$ & $8.25 \pm 0.22^{\mathrm{a}}$ & $8.09 \pm 0.15^{\mathrm{a}}$ & $35.32 \pm 0.73^{\mathrm{b}}$ & $30.36 \pm 1.67^{\mathrm{c}}$ \\
\% Body weight & $2.91 \pm 0.05^{\mathrm{a}}$ & $2.70 \pm 0.40^{\mathrm{b}}$ & $7.33 \pm 0.17^{\mathrm{c}}$ & $5.68 \pm 0.36^{\mathrm{d}}$ \\
Steatosis score & $1.53 \pm 0.11^{\mathrm{a}}$ & $1.00 \pm 0.00^{\mathrm{b}}$ & $4.90 \pm 0.06^{\mathrm{c}}$ & $3.16 \pm 0.27^{\mathrm{d}}$ \\
\hline
\end{tabular}

Lower-case letters (a, b, c, d) indicate statistically significant differences between groups, $P<0.01$

* Number of animals

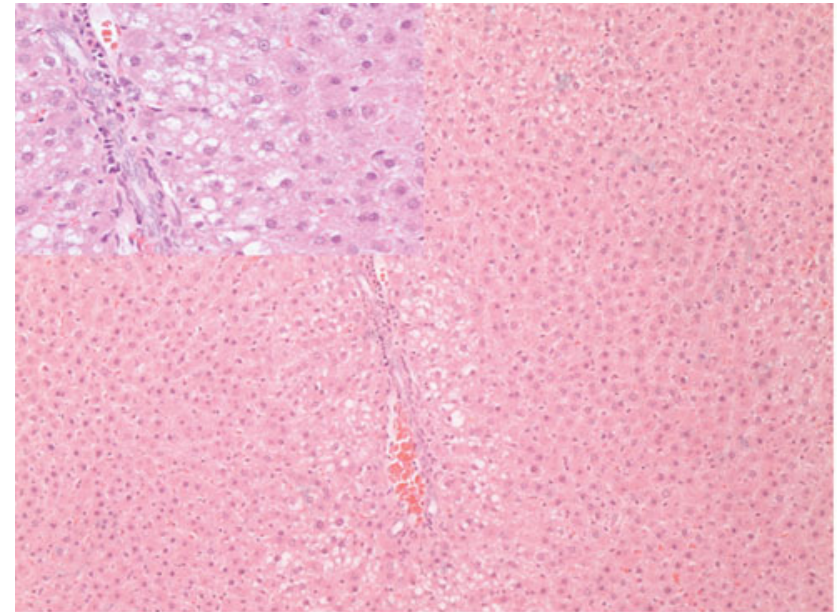

Lean Casein

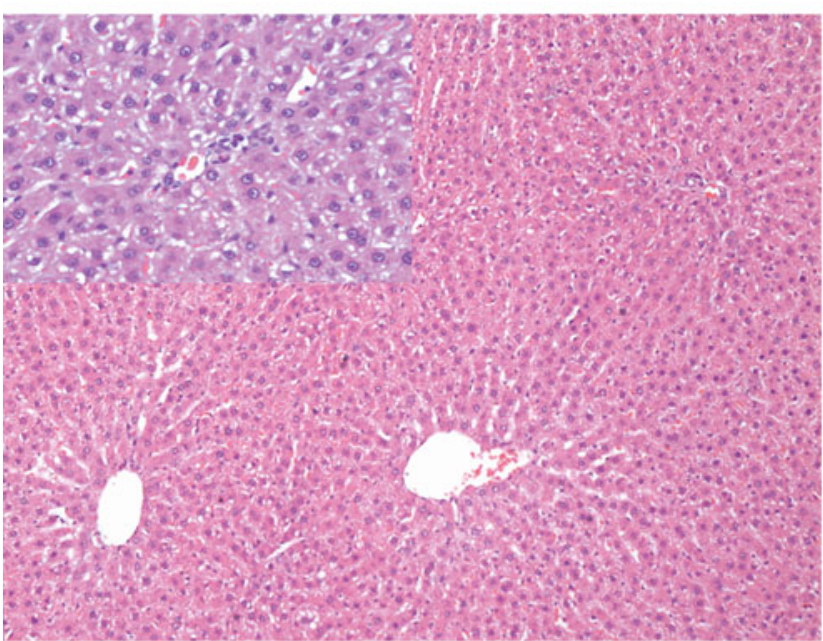

Lean Soy

Fig. 1 Upper left liver from a casein-fed lean rat showing minimal steatosis, original magnification $100 \times$, insert $200 \times$; Lower left liver from a lean soy-fed rat showing normal hepatic parenchyma with no steatosis, original magnification $100 \times$, insert $200 \times$; Upper right liver from an obese casein-fed rat showing marked steatosis $(>75 \%$ of

soy-fed rats had a lower steatosis score compared to lean casein-fed rats (Table 3). Data demonstrate that obesity increased liver steatosis, whereas the soy diet significantly reduced steatosis in both the lean and obese animal groups.

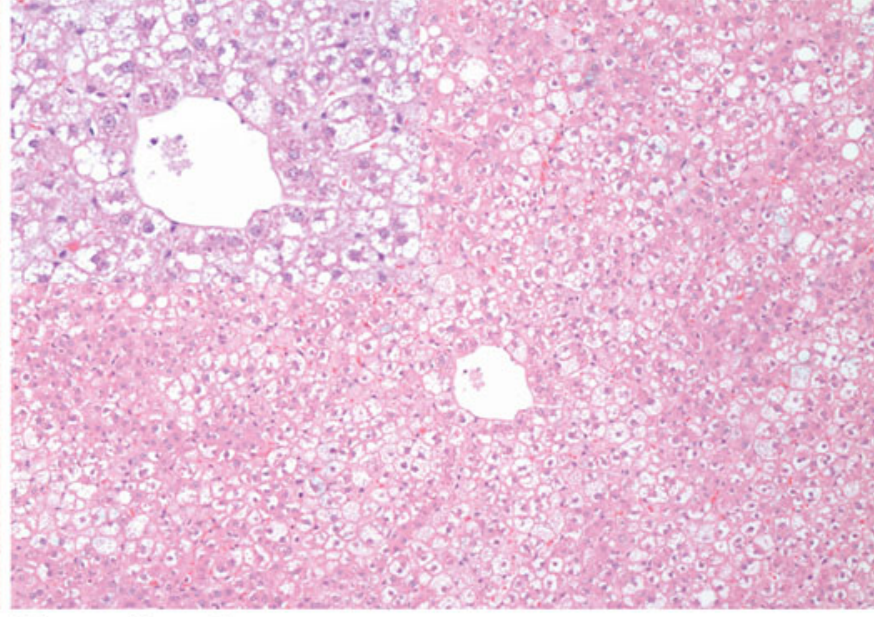

\section{Obese Casein}

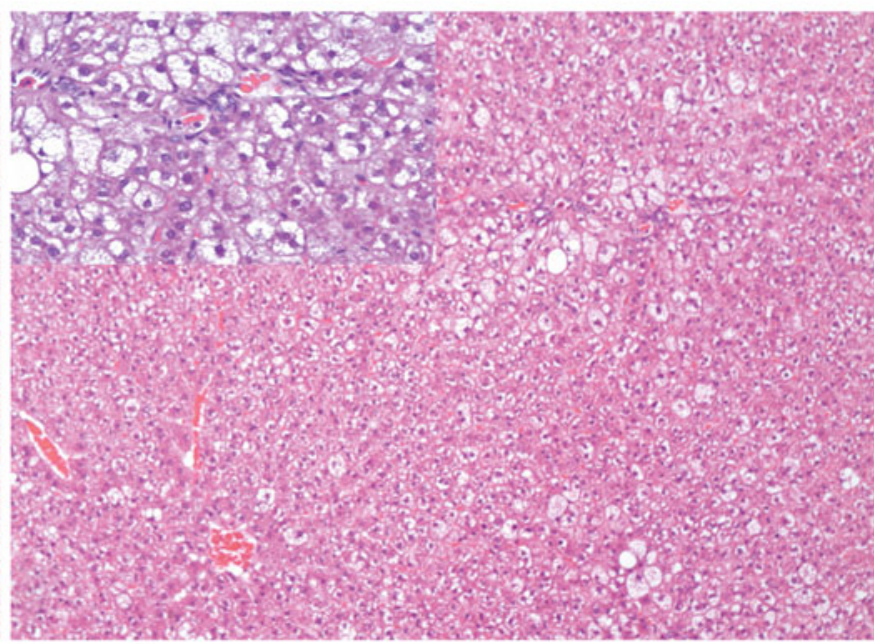

Obese Soy

hepatocytes exhibited microvesicular and macrovesicular steatosis), original magnification $100 \times$, insert $200 \times$; Lower right: liver from an obese soy-fed rat showing less steatosis ( $\sim 25 \%$ of hepatocytes exhibited microvesicular and macrovesicular steatosis), original magnification $100 \times$, insert $200 \times$

\section{Liver gene expression}

Figure 2 depicts effects of obesity and dietary protein type on relative abundance of mRNAs encoding: (a) the lipogenic enzyme pathway members Fatty Acid Synthase 
(FASN), Malic Enzyme 1 (ME1), Glucose 6-Phosphate Dehydrogenase (G6PD), 6-Phosphogluconate Dehydrogenase (6PGD), and Sterol Regulatory Element Binding Protein-1c (SREBP-1c), and (b) thyroid hormone system proteins Thyroid Receptor Alpha 1 (TR $\alpha 1)$, Thyroid Receptor Beta 1 (TR $\beta 1)$, Iodothyronine Deiodinase 1 (DIO1) and Iodothyronine Deoidinase 2 (DIO2). When comparing between lean casein-fed and obese casein-fed rats, obesity was found to be associated with significant reductions in hepatic transcript abundance for G6PD, 6PGD, TR $\alpha 1, \mathrm{TR} \beta 1$ and DIO1 (Fig. 2). Obesity had no effect on hepatic mRNA levels for FASN, ME1, SREBP-1c and DIO2 when comparing between casein-fed lean and casein-fed obese animals. The soy protein diet was associated with increased expression of FASN, ME1, 6PGD and SREBP-1c genes in livers of obese (but not lean) rats and with decreased expression of the 6PGD gene in lean rats. Western blots showed a significant induction of ME1 protein expression in the obese soy protein-fed rats
(Fig. 3), paralleling the induction of ME1 mRNA abundance (Fig. 2).

Figure 4 shows effects of obesity and dietary protein type on abundance of hepatic mRNAs encoding four key proteins of cholesterol metabolism. Obesity was associated with inductions in LXR $\alpha$ and CYP7A1 transcripts, whereas diet had no effect on expression of these two genes. The soy protein diet lowered expression of HMGCR in lean but not obese animals. Interestingly, SREBP-2 mRNA abundance was greatest for the soy protein-fed obese rats, with that for casein-fed obese rats falling in between that for the lean rats (Fig. 4).

Serum insulin concentrations

Figure 5 depicts effects of obesity and type of dietary protein on serum insulin concentration. The obese state was characterized by marked hyperinsulinemia, which was further exacerbated by the soy protein isolate-based diet.
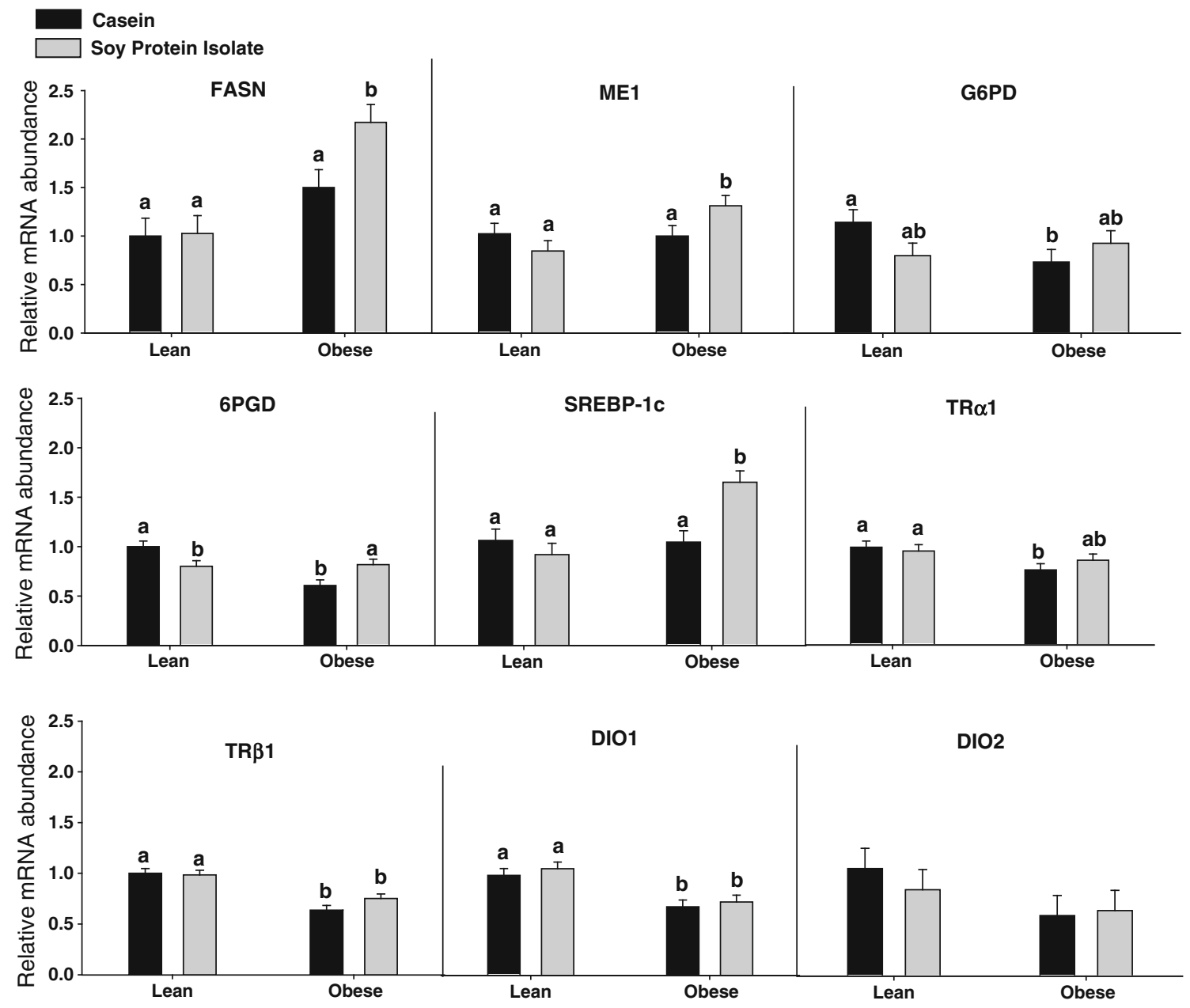

Fig. 2 Effects of obesity and type of dietary protein on hepatic mRNA abundance of lipogenic and thyroid hormone system genes ( $n=9$ animals per group). Liver transcripts were normalized using a factor derived from the geometric mean of $\beta$ actin, cyclophilin A and TBP, calculated with GeNorm software. Lower-case letters indicate significant differences between treatment groups, $P<0.05$ 

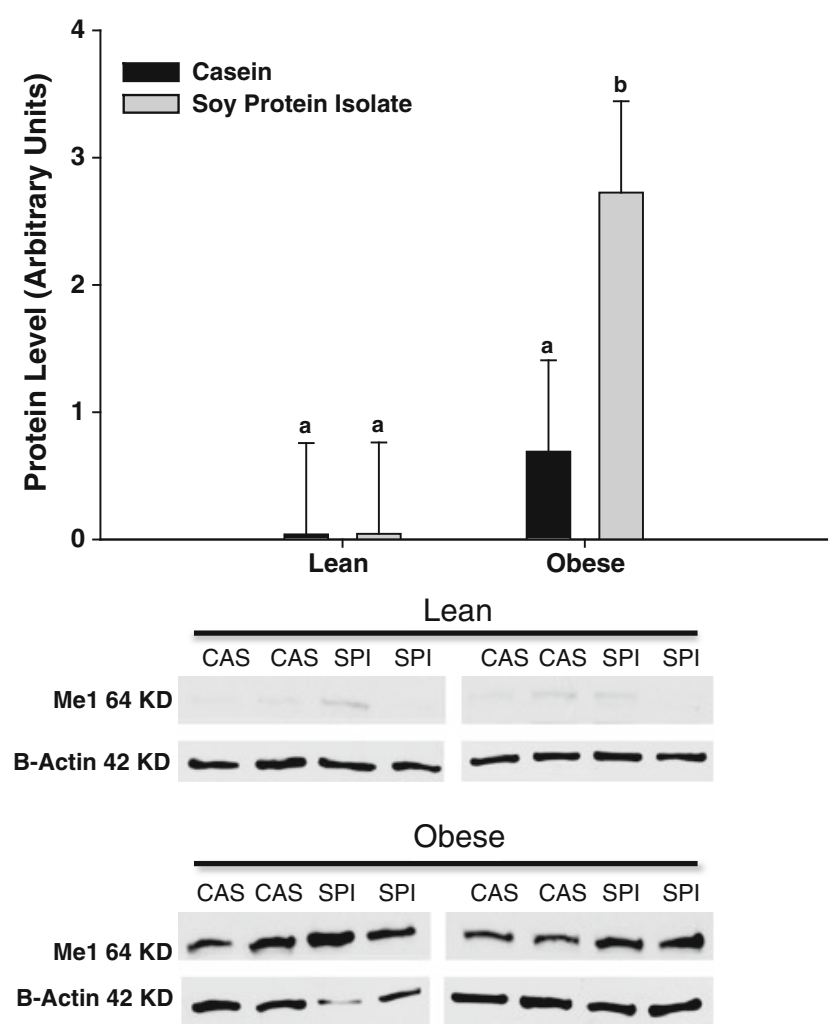

Fig. 3 Western blot of ME1 in rat livers ( $n=4$ animals per group). $\beta$ actin served as the loading control. Data in bar graphs represent that after scanning of X-ray films and normalization to $\beta$ actin. Lowercase letters indicate significant differences between treatment groups, $P<0.05$

\section{Discussion}

The present study was designed to elucidate molecular mechanism(s) for the dietary soy protein-promotion of mammary tumor incidence and tumor outcome in obese Zucker rats, given previous studies in other rodent models documenting mammary tumor-preventive effects of soy consumption (Hakkak et al. 2000; Simmen et al. 2005). In addition, to the best of our knowledge, the current work was a first attempt to model dietary prevention of hepatic steatosis in the obese state during breast cancer, pathologies that often occur together in women (Bilici et al. 2007; Chu et al. 2003; Nguyen et al. 2001). Previously, we reported that the soy protein diet caused an increase in mammary tumor incidence and shortened mammary tumor latency specifically in obese Zucker rats that were subjected to DMBA-induced mammary tumorigenesis (Hakkak et al. 2011). In addition, the obese soy-fed rats had the greatest frequency of more pathologically advanced mammary tumors, among all groups examined (Hakkak et al. 2011). Results presented herein for these same animals indicate striking dietary influences on hepatic molecular biology that likely impacted lipogenesis and cholesterogenesis, which we speculate enhanced mammary tumor outcome in the obese rats.

Our findings underscore obesity and its attendant hypothyroidism as major risk factors for NAFLD during mammary carcinogenesis. Results suggest that the lipolytic and thermogenic actions of thyroid hormone signaling in liver cells are suppressed (due to decreased expression of TR and DIO1 genes) in obese Zucker rats, which would favor lipid accumulation, body weight gain and fatty liver formation. The decreased steady-state expression of the two pentose phosphate pathway enzyme genes (G6PD and 6PGD) observed with obesity further supports the concept of a generally hypothyroid state of the obese Zucker rat, as these genes are thyroid hormone-induced. Increased body weight during obesity is not the sole basis for NAFLD in this animal model, since we observed that diet could affect its manifestation. Obese soy-fed rats gained significantly more weight than did obese casein-fed rats. However, despite the increased body weight gain with soy protein diet, liver weights and liver steatosis were decreased compared to the casein-fed obese group.

Multiple studies have reported that soy protein-based diets lower serum cholesterol and triglycerides and reduce liver synthesis/accumulation of cholesterol and triglycerides, thereby leading to less liver steatosis (Anderson et al. 1995; Ascencio et al. 2004; Gudbrandsen et al. 2005, 2006, 2009; Tovar et al. 2002, 2005; Wergedahl et al. 2004; Zhan and Ho 2005). Severity of hepatosteatosis typically is correlated with the relative activity of lipogenic genes (Buque et al. 2010), and in some cases, soy protein consumption protected against hepatosteatosis via suppression of these genes (Torre-Villalvazo et al. 2008; Tovar et al. 2005). However, in the obese/mammary cancer model used here, expression analysis of the lipogenic pathway genes FASN, ME1, 6PGD, SREBP-1c and of the cholesterol synthesis-associated transcription factor SREBP-2 revealed significant inductions for each in livers from obese soy-fed rats. These results indicate that the fatty acid biosynthetic pathway was up-regulated by soy protein diet, perhaps as a consequence of elevated insulin levels, in livers of obese (but not lean) rats previously administered mammary carcinogen. Similarly, the elevations in hepatic SREBP-2 expression suggest increased cholesterol synthesis in the soy protein-fed obese rats.

As mentioned above, the protective effect of soy protein diet on steatosis ran counter to the observed increase in lipogenic gene expression. Multiple other mechanisms may therefore underlie soy protein protection against liver steatosis observed here. One apparent possibility relates to the inverse association between insulin resistance and NAFLD (Browning et al. 2004), as soy protein isolates are known to enhance insulin sensitivity in rodent models. However, it is not obvious how the soy protein diet may have enhanced 
Fig. 4 Expression of cholesterol metabolism-related genes in the livers of lean and obese Zucker rats fed casein or soy protein diets ( $n=7$ animals per group). Liver transcripts were normalized using a factor derived from the geometric mean of 18S rRNA, cyclophilin A and TBP, calculated with GeNorm software. Lower-case letters indicate significant differences between treatment groups, $P<0.05$
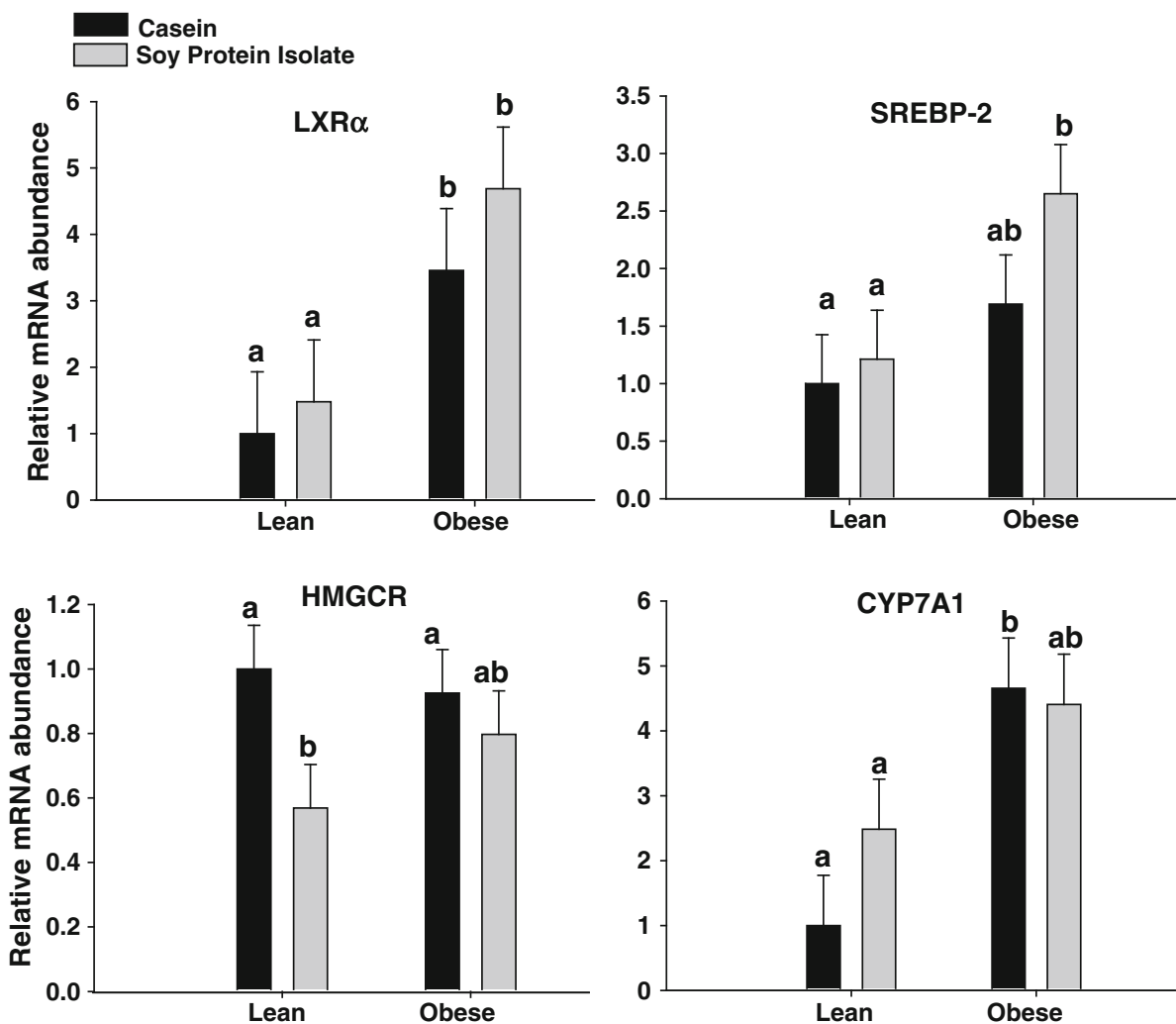

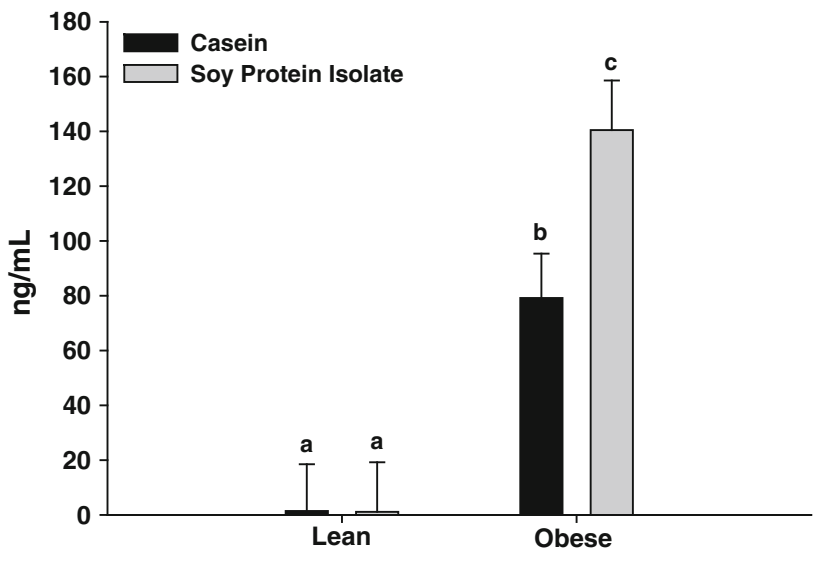

Fig. 5 Soy protein diet resulted in elevated serum insulin levels in female obese Zucker rats exposed to DMBA. Data are means \pm SEM for 8-10 animals/group. Lower-case letters indicate statistically significant differences between groups (two-way ANOVA, $P$ for $a$ vs. $b$ is $<0.001$ and for $b$ vs. $c$ is 0.017 )

insulin sensitivity, while at the same time resulting in an elevation in circulating insulin levels as observed here. Dietary soy protein increased hepatic fatty acid oxidation via induction of peroxisome proliferator-activated receptor- $\alpha$ (PPAR- $\alpha)$ (Mezei et al. 2003), perhaps a similar pathway effect is operative here. Obese Zucker diabetic rats fed soy-based diet had more, but smaller sized, adipocytes than did casein-fed rats; thus, soy protein diet may suppress hypertrophy and stimulate hyperplasia of adipocytes, thereby affecting adipocytokine secretion and signaling to hepatocytes (Mezei et al. 2003). In the lean rats of the current study, soy protein diet lowered expression of HMGCR, which may have contributed to less cholesterol synthesis and steatosis in these animals. However, such an effect was not observed in the obese animals. In fact, our data for SREBP-2 are suggestive of increased cholesterol synthesis in soy protein-fed obese rats. CYP7A1 levels were greater in obese rats, presumably leading to increased bile acid production; however, diet had no effect on this gene's expression. Enhanced expression of LXR $\alpha$ in obese rats undoubtedly contributed to their increased adiposity.

It is reasonable to speculate that the enhanced hepatic lipogenic enzyme gene expression profile observed with the soy protein diet contributed to the increases in weight gain, adiposity and mammary tumorigenesis of obese Zucker rats fed this diet. Obese Zucker rats are hypothyroid and hyperinsulinemic (Spydevold et al. 1978). As demonstrated here, the soy protein-based diet further enhanced the circulating levels of insulin and this, coupled with the high steady-state levels of circulating IGF-I (Hakkak et al. 2011), in all likelihood led to the observed inductions of the insulin- and IGF-responsive hepatic FASN, ME1, 6PGD and SREBP-1c genes. In this regard, ME1 is a central regulator of adiposity in humans and rodents (Yang et al. 2009) and the induction in its hepatic expression at both mRNA and protein levels is consistent with the effect 
of soy protein on body weight of obese Zucker rats. Future studies should address functional linkages of diet and obesity with hepatic lipogenesis, triglyceride and cholesterol outputs, and mammary tumorigenesis.

In summary, long-term soy protein consumption suppressed hepatic steatosis in obese female rats bearing mammary tumors, while enhancing mammary tumorigenesis. The effects of soy protein isolate to further induce already elevated circulating insulin levels is likely to have caused secondary inductions of hepatic fatty acid synthesis and triglyceride secretion via the pathways involving the SREBP-1c, ME1 and FASN proteins. It is likely that the elevated circulating insulin levels exerted direct growth promoting and anti-apoptotic actions on initiated mammary tumor cells. Further, increased serum triglycerides and cholesterol with soy protein feeding may have augmented mammary tumorigenesis in the obese state. Since human obesity leads to hypothyroid and hyperinsulinemic states, data presented here may have implications for dietary regimens for obese women with breast cancer. The further understanding of how dietary constituents such as soy proteins and isoflavones, which affect hepatic lipogenic gene expression, insulin resistance, hepatosteatosis, and thyroid system actions, mediate tumorigenesis in obese individuals is requisite for improved breast cancer outcome.

Acknowledgments This work was supported by NIH Grant RO1 CA136493 (F.A.S), US Department of Agriculture Award No. 2007-35200-17793 (R.H.), The Arkansas Biosciences Institute (R.H.), and NIH NCRR Grant UL1RR029884 (UAMS). We thank Dr. Rosalia C.M. Simmen for a helpful critique of the manuscript. We wish to thank John Gregan for valuable assistance in prepration of this manuscript.

\section{References}

Anderson JW, Johnstone BM, Cook-Newell ME (1995) Meta-analysis of the effects of soy protein intake on serum lipids. N Engl J Med 333:276-282

Angulo P (2002) Treatment of nonalcoholic fatty liver disease. Ann Hepatol 1:12-19

Ascencio C, Torres N, Isoard-Acosta F, Gomez-Perez FJ, HernandezPando R, Tovar AR (2004) Soy protein affects serum insulin and hepatic SREBP-1 mRNA and reduces fatty liver in rats. J Nutr 134:522-529

Bilici A, Ozguroglu M, Mihmanli I, Turna H, Adaletli I (2007) A case-control study of non-alcoholic fatty liver disease in breast cancer. Med Oncol 24:367-371

Bray GA, York DA, Fisler JS (1989) Experimental obesity: a homeostatic failure due to defective nutrient stimulation of the sympathetic nervous system. Vitam Horm 45:1-125

Browning JD, Szczepaniak LS, Dobbins R, Nuremberg P, Horton JD, Cohen JC, Grundy SM, Hobbs HH (2004) Prevalence of hepatic steatosis in an urban population in the United States: impact of ethnicity. Hepatology 40:1387-1395

Buque X, Martinez MJ, Cano A, Miquilena-Colina ME, GarciaMonzon C, Aspichueta P, Ochoa B (2010) A subset of dysregulated metabolic and survival genes is associated with severity of hepatic steatosis in obese Zucker rats. J Lipid Res 51:500-513

Chu CH, Lin SC, Shih SC, Kao CR, Chou SY (2003) Fatty metamorphosis of the liver in patients with breast cancer: possible associated factors. World J Gastroenterol 9:1618-1620

Chua SC Jr, Chung WK, Wu-Peng XS, Zhang Y, Liu SM, Tartaglia L, Leibel RL (1996) Phenotypes of mouse diabetes and rat fatty liver due to mutations in the OB (leptin) receptor. Science 271:994-996

Day CP (2005) Natural history of NAFLD: remarkably benign in the absence of cirrhosis. Gastroenterology 129:375-378

Gudbrandsen OA, Wergedahl H, Liaset B, Espe M, Berge RK (2005) Dietary proteins with high isoflavone content or low methionineglycine and lysine-arginine ratios are hypocholesterolaemic and lower the plasma homocysteine level in male Zucker fa/fa rats. Br J Nutr 94:321-330

Gudbrandsen OA, Wergedahl H, Mork S, Liaset B, Espe M, Berge RK (2006) Dietary soya protein concentrate enriched with isoflavones reduced fatty liver, increased hepatic fatty acid oxidation and decreased the hepatic mRNA level of VLDL receptor in obese Zucker rats. Br J Nutr 96:249-257

Gudbrandsen OA, Wergedahl H, Berge K (2009) A casein diet added isoflavone-enriched soy protein favorably affects biomarkers of steatohepatitis in obese Zucker rats. Nutrition 25:574-580

Hakkak R, Korourian S, Shelnutt SR, Lensing S, Ronis MJ, Badger TM (2000) Diets containing whey proteins or soy protein isolate protect against 7,12-dimethylbenz(a)anthracene-induced mammary tumors in female rats. Cancer Epidemiol Biomarkers Prev 9:113-117

Hakkak R, Shaaf S, Jo C, MacLeod S, Korourian S (2011) Effects of high-isoflavone soy diet vs. casein protein diet and obesity on DMBA-induced mammary tumor development. Oncology Lett 2:29-36

Kris-Etherton PM, Hecker KD, Bonanome A, Coval SM, Binkoski AE, Hilpert KF, Griel AE, Etherton TD (2002) Bioactive compounds in foods: their role in the prevention of cardiovascular disease and cancer. Am J Med 113(Supp 9B):71S-88S

Mezei O, Banz WJ, Steger RW, Peluso MR, Winters TA, Shay N (2003) Soy isoflavones exert antidiabetic and hypolipidemic effects through the PPAR pathways in obese Zucker rats and murine RAW 264.7 cells. J Nutr 133:1238-1243

Mokdad AH, Ford ES, Bowman BA, Dietz WH, Vinicor F, Bales VS, Marks JS (2003) Prevalence of obesity, diabetes, and obesityrelated health risk factors, 2001. JAMA 289:76-79

Nguyen MC, Stewart RB, Banerji MA, Gordon DH, Kral JG (2001) Relationships between tamoxifen use, liver fat and body fat distribution in women with breast cancer. Int J Obes Relat Metab Disord 25:296-298

Ong JP, Younossi ZM (2007) Epidemiology and natural history of NAFLD and NASH. Clin Liver Dis 11:1-16

Peeters PH, Keinan-Boker L, van der Schouw YT, Grobbee DE (2003) Phytoestrogens and breast cancer risk. Review of the epidemiological evidence. Breast Cancer Res Treat 77:171-183

Roberts EA (2007) Pediatric nonalcoholic fatty liver disease (NAFLD): a "growing" problem? J Hepatol 46:1133-1142

Simmen RCM, Eason RR, Till SR, Chatman L Jr, Velarde MC, Geng Y, Korourian S, Badger TM (2005) Inhibition of NMU-induced mammary tumorigenesis by dietary soy. Cancer Lett 224:45-52

Simmen FA, Mercado CP, Zavacki AM, Huang SA, Greenway AD, Kang P, Bowman MT, Prior RL (2010) Soy protein diet alters expression of hepatic genes regulating fatty acid and thyroid hormone metabolism in the male rat. J Nutr Biochem 21:11061113

Sinha MK, Opentanova I, Ohannesian JP, Kolaczynski JW, Heiman ML, Hale J, Becker GW, Bowsher RR, Stephens TW, Caro JF (1996) Evidence of free and bound leptin in human circulation. 
Studies in lean and obese subjects and during short-term fasting. J Clin Invest 98:1277-1282

Spydevold SO, Greenbaum AL, Baquer NZ, McLean P (1978) Adaptive responses of enzymes of carbohydrate and lipid metabolism to dietary alteration in genetically obese Zucker rats (fa/fa). Eur J Biochem 89:329-339

Tartaglia LA, Dembski M, Weng X, Deng N, Culpepper J, Devos R, Richards GJ, Campfield LA, Clark FT, Deeds J et al (1995) Identification and expression cloning of a leptin receptor, OB-R. Cell 83:1263-1271

Torre-Villalvazo I, Tovar AR, Ramos-Barragan VE, Cerbon-Cervantes MA, Torres N (2008) Soy protein ameliorates metabolic abnormalities in liver and adipose tissue of rats fed a high fat diet. J Nutr 138:462-468

Tovar AR, Murguia F, Cruz C, Hernandez-Pando R, Aguilar-Salinas CA, Pedraza-Chaverri J, Correa-Rotter R, Torres N (2002) A soy protein diet alters hepatic lipid metabolism gene expression and reduces serum lipids and renal fibrogenic cytokines in rats with chronic nephrotic syndrome. J Nutr 132:2562-2569

Tovar AR, Torre-Villavazo I, Ochoa M et al (2005) Soy protein reduces hepatic lipotoxicity in hyperinsulinemic obese Zucker fa/fa rats. J Lipid Res 46:1823-1832

Vandesompele J, De Preter K, Pattyn F, Poppe B, Van Roy N, De Paepe A, Speleman F (2002) Accurate normalization of real-time quantitative RT-PCR data by geometric averaging of multiple internal control genes. Genome Biol 3:RESEARCH0034
Wergedahl H, Liaset B, Gudbrandsen OA, Lied E, Espe M, Muna Z, Mork S, Berge RK (2004) Fish protein hydrolysate reduces plasma total cholesterol, increases the proportion of HDL cholesterol, and lowers acyl-CoA:cholesterol acyltransferase activity in liver of Zucker rats. J Nutr 134:1320-1327

National Center for Health Statistics. http://www.cdc.gov/nchs/ nhanes.htm. National Health and Nutrition Examination Survey

WHO. http://www.who.int/nut/obs.htm. World Health Organization

Yang X, Deignan JL, Qi H, Zhu J, Qian S, Zhong J, Torosyan G, Majid S, Falkard B, Kleinhanz RR, Karlsson J, Castellani LW, Mumick S, Wang K, Xie T, Coon M, Zhang C, Estrada-Smith D, Farber CR, Wang SS, van Nas A, Ghazalpour A, Zhang B, Macneil DJ, Lamb JR, Dipple KM, Reitman ML, Mehrabian M, Lum PY, Schadt EE, Lusis AJ, Drake TA (2009) Validation of candidate causal genes for obesity that affect shared metabolic pathways and networks. Nat Genet 41:415-423

Zhan S, Ho SC (2005) Meta-analysis of the effects of soy protein containing isoflavones on the lipid profile. Am J Clin Nutr 81:397-408

Zucker LM (1972) Fat mobilization in vitro and in vivo in the genetically obese Zucker rat "fatty". J Lipid Res 13:234-243

Zucker L, Zucker TF (1961) Fatty, a new mutation in the rat. J Heredity 52:275-278

Zucker TF, Zucker LM (1963) Fat accretion and growth in the rat. J Nutr 80:6-19 